\title{
The antiapoptotic activity of insect IAPs requires activation by an evolutionarily conserved mechanism
}

\author{
T Tenev ${ }^{1,2}$, M Ditzel $^{1,2}$, A Zachariou ${ }^{1}$ and P Meier ${ }^{\star, 1}$
}

Apoptosis represents a fundamental biological process that relies on the activation of caspases. Inhibitor of apoptosis (IAP) proteins represent a group of negative regulators of both caspases and cell death. The current model dictates that IAPs suppress apoptosis by blocking the catalytic pocket of effector caspases thereby preventing substrate entry. Here, we provide evolutionary evidence for the functional interplay between insect IAPs and the $\mathrm{N}$-end rule-associated ubiquitylation machinery in neutralising effector caspases and cell death. We find that IAPs require 'priming' in order to function as antiapoptotic molecules. Consistently, we demonstrate that the antiapoptotic activity of diverse insect IAPs is activated by effector caspases, providing the cell with a sensitive strategy to monitor and neutralise active caspases. Almost 300 million years of evolutionary selection pressure has preserved a caspase cleavage site in insect IAPs that, following processing by a caspase, exposes a binding motif for the N-end-rule-associated degradation machinery. Recruitment of this ubiquitylation machinery into the 'cleavedIAP:caspase' complex provides a mechanism to negatively regulate effector caspases and block apoptosis. Furthermore, comparisons between cellular and several viral IAPs suggest differences in their modes of action, as OpIAP3, CpGV-IAP3 and HcNPV-IAP3 fail to associate with several effector caspases. Evolutionary conservation of the $\mathrm{N}$-end-rule degradation pathway in IAP-mediated regulation of apoptosis further corroborates the physiological relevance of this ubiquitylation-associated process. Cell Death and Differentiation (2007) 14, 1191-1201. doi:10.1038/sj.cdd.4402118; published online 9 March 2007

Regulation of apoptosis is crucial to ensure cellular viability and failure to do so is linked to several human pathologies. ${ }^{1}$ Inhibitor of apoptosis proteins(IAPs) are negative regulators of apoptosis that suppress cell death by directly regulating caspases. $^{2}$ Initiator caspases reside at the tip of the caspase cascade, and once activated cleave and activate downstream effector caspases, which in turn proteolyse a wide range of substrates leading to cell death. The ability of IAPs to regulate this caspase cascade, and hence apoptosis, resides in their ability to block both initiator and effector caspases. ${ }^{3}$

In Drosophila, DIAP1 represents an essential negative regulator of the initiator caspase DRONC and the effector caspases drICE and DCP-1. ${ }^{4}$ Deletion or mutation of DIAP1 leads to spontaneous induction of apoptosis both in vivo and ex vivo. ${ }^{4}$ Direct physical interaction with effector caspases (drICE or DCP-1) and initiator caspase (DRONC) is mediated through DIAP1's BIR1 and BIR2 (Baculoviral IAP Repeat) domains, respectively. DIAP1's BIR2:DRONC association is essential for DIAP1 to neutralise DRONC. ${ }^{5-7}$ However, mere binding alone, although necessary, is not sufficient for DIAP1mediated inhibition of DRONC. Following binding, DIAP1's C-terminal RING-finger (RING) domain promotes ubiquitin (Ub) conjugation of DRONC, and mutation in this domain cause a severe loss-of-function phenotype in vivo. ${ }^{5}$

Degradation by the ubiquitin-proteasome system (UPS) determines the stability of a wide range of intracellular proteins. Degradation by one particular branch of the UPS, known as the $\mathrm{N}$-end rule degradation (NERD) pathway, is determined by a substrates' amino $\left(\mathrm{NH}_{2}\right)$-terminal residue. ${ }^{8}$ The combination of a protein's $\mathrm{NH}_{2}$-terminal amino acid with an internal lysine (Lys) residue, which acts as the site of Ub-conjugation, defines the substrate's degradation signal or $\mathrm{NH}_{2}$-terminal degron ( $\mathrm{N}$-degron). ${ }^{8}$ Accordingly, a relationship exists between a protein's half-life and the amino acid of the $\mathrm{NH}_{2}$-terminal degron, with certain amino acids being destabilising residues. Exposure of a destabilising residue leads to the creation of a binding site for $\mathrm{N}$-end-rule-specific ubiquitinprotein ligases. ${ }^{9,10}$ These specialised E3s, once bound to their substrates, target them for poly-ubiquitylation. Hence, an N-degron-bearing-protein's half-life is, therefore, not an intrinsic property of the $\mathrm{NH}_{2}$-terminal residue itself, but the result of its binding to an E3. Insights into the function of $\mathrm{N}$-end-rule-based processes are only just beginning to emerge. ${ }^{11-13}$ The fundamental physiological importance of the NERD pathway is highlighted by the fact that $\mathrm{N}$-end-ruledirected degradation is conserved from prokaryotes ${ }^{14}$ to all of the eukaryotes examined. ${ }^{9}$

Previous work has shown that Drosophila effector caspases bind and cleave DIAP1 at its $\mathrm{NH}_{2}$-terminus, ${ }^{15-17}$ which leads to DIAP1's degradation by the $\mathrm{N}$-end-rule machinery. ${ }^{15}$ Although DIAP1-cleavage and subsequent degradation seems to be essential for DIAP1's antiapoptotic activity, ${ }^{15,18}$ the contribution of the NERD pathway in apoptotic regulation

\footnotetext{
${ }^{1}$ The Breakthrough Toby Robins Breast Cancer Research Centre, Institute of Cancer Research, Chester Beatty Laboratories, London UK

${ }^{*}$ Corresponding author: P Meier, The Breakthrough Toby Robins Breast Cancer Research Centre, Institute of Cancer Research, Mary-Jean Mitchell Green Building, Chester Beatty Laboratories, Fulham Road, London SW3 6JB, UK. Tel: + 44 (0)20 7153 5326; Fax: + 44 (0)20 7153 5340; E-mail: pmeier@icr.ac.uk

${ }^{2}$ These authors contributed equally to this work

Keywords: apoptosis; IAPs; Drosophila; IAP antagonist; N-end rule; caspase

Abbreviations: IAP, Inhibitor of apoptosis proteins; UPS, ubiquitin-proteasome system; NERD, N-end rule degradation

Received 05.9.06; revised 22.1.07; accepted 28.1.07; Edited by DL Vaux; published online 09.3.07
} 
remains controversial and awaits validation. ${ }^{19}$ Moreover, this DIAP1-associated antiapoptotic mechanism has, so far, not been observed outside of the Drosophila genus. To gain insights into the relevance of the $\mathrm{N}$-end-rule-based antiapoptotic mechanism, we studied the effects of almost 300 million years of evolutionary selection pressure ${ }^{20}$ on IAP-mediated caspase regulation. Through comparison of various insect IAPs, ranging from Diptera, Lepidoptera and Hymenoptera, we uncovered a striking mechanistic conservation in caspase regulation. We find that caspase-mediated cleavage of insect IAPs is required to potentiate the IAPs' antiapoptotic activity. Intriguingly, viral IAPs lack the determinants for caspasemediated cleavage and engagement of the NERD pathway. Consistent with the absence of the N-end-rule-based mechanism for viral IAPs, we find that the viral IAPs OpIAP3, CpGV-IAP3 and HcNPV-IAP3 are unable to physically associate with effector caspases. By contrast, cellular insect IAPs stably associate with effector caspases. For their full antiapoptotic potential, cellular insect IAPs need to be 'activated' by caspase-mediated proteolysis. Therefore, cellular IAPs seem to function as 'mechanism-based' inhibitors that rely on the catalytic activity of the protease they inhibit.

\section{Results}

Evolutionary conservation of an $\mathrm{NH}_{2}$-terminal caspase cleavage site and a destabilising Asn at the $P_{\mathbf{1}}$, subsite. Protein motifs with vital physiological functions are conserved by evolutionary selection pressure. Hence, the degree of evolutionary conservation of a protein's aminoacid sequence can be used to identify potentially important motifs. We compared the primary sequence of a number of insect IAPs of Diptera, Lepidoptera and Hymenoptera groups spanning more than 290 million years. ${ }^{21}$ In particular, we focused on IAPs with a domain architecture of IAP1 from Drosophila melanogaster (DIAP1), which carries two BIR domains and a C-terminal RING finger. IAPs of this type seem to be critically important for cell survival ${ }^{5,22-24}$ whereas IAPs with three BIR domains and a C-terminal RING finger do not cause any obvious cell death phenotypes when mutated. ${ }^{25-27}$ In addition to the IAP-family-defining BIR and RING domains, we found that an $\mathrm{NH}_{2}$-terminal caspase cleavage motif (DXXD, Figure 1a), initially seen in DIAP1, ${ }^{15}$ was absolutely conserved. Apart from the BIR, RING and caspase cleavage motif, no other protein stretch was conserved to the same extent (data not shown). The localisation of the caspase cleavage motif, nine to 25 amino acids $\mathrm{NH}_{2}$-terminal to the first BIR domain, was also preserved across all species examined. Equally apparent was the absolute conservation of an asparagine (Asn) residue at the caspase cleavage site's $P_{1}$ ' position (DXXD $\downarrow \underline{N}$ ), C-terminal to the scissile bond that is subject to cleavage. In comparison only one other residue, DIAP1's glutamate at position 44, was conserved within the region between the DXXD $\downarrow N$ motif and the start of the BIR1. Interestingly, whereas viral IAPs are highly conserved over the BIR and RING domains, comparison with a number of viral IAPs (Figure 1a) revealed that these IAPs lacked the DXXD motif or the $\mathrm{P}_{1}$ ' Asn residue as seen in insect cellular IAPs. Although some of the viral IAPs carry a aspartate residue in their $\mathrm{N}$-peptide sequence, effector caspases have a preference for DXXD motifs ${ }^{28}$ and display a strong selectivity for certain residues in the $\mathrm{P} 1$ ' position, ${ }^{29}$ with small residues ( $\mathrm{G}, \mathrm{S}, \mathrm{A}$ and $\mathrm{N}$ ) being well tolerated, whereas charged amino acids are completely prohibited. Of the viral IAPs examined, only BmNVP-IAP1 carries a DN sequence, however, it is not preceded by a DXXD motif. The high degree of evolutionary conservation of the $D X X D \downarrow N$ motif in very distant cellular IAPs, with the most divergent species, Drosophila to Apis, spanning more than 290 million years (Figure 1b), strongly suggests that this motif serves an important function.

Insect IAPs are cleaved at the conserved DXXD $\downarrow N$ motif. In light of the conserved caspase-cleavage site and the $\mathrm{N}$-end-rule residue across distant insect species, we tested whether $\mathrm{N}$-end-rule-mediated regulation of cell death is evolutionarily conserved. We selected representative IAPs from species of three insect groups: DIAP1 from $D$. melanogaster, AglAP3 from A. gambiae, AalAP from A. aegypti, BmIAP from B. mori and SfIAP from $S$. frugiperda. For NERD pathway initiation, effector caspases must cleave IAPs at their $\mathrm{NH}_{2}$-terminus. To assess IAP cleavage, purified IAPs were exposed to the effector caspases drICE or DCP-1. To this end, TAP (tandem affinity purification ${ }^{30}$ )-tagged insect IAPs were expressed in 293T cells and purified using the TAP system (see Materials and Methods for details). Note, to detect IAP cleavage more easily, we used the N-terminal half of these IAPS (IAP-BIR1 region) that is smaller in size than full-length proteins and thereby aids visualization of differences in mobility in SDS-PAGE. This region includes the putative cleavage site and the BIR1 domain, which is required for caspase binding (see below). Following tandem affinity purification, IAPs were incubated with purified active drICE. Active drICE was generated by expressing V5/His-tagged drICE in 293T cells and purified from cellular extracts using nickel beads. All insect cellular IAPs analysed were cleaved by the Drosophila effector caspase drICE and DCP-1 (Figure 2a, and data not shown). Analysis of the resulting cleavage fragment revealed an apparent molecular mass consistent with cleavage at the predicted DXXD $\downarrow N$ caspase cleavage site. By contrast, and

\footnotetext{
Figure 1 The $\mathrm{NH}_{2}$-terminal caspase cleavage site and Asn at the P1' subsite is evolutionarily conserved in insect cellular IAPs but not in viral IAPs. Note, this study focuses exclusively on IAPs with a domain architecture of two BIR domains and a C-terminal RING finger. (a) ClustalX alignment of the $\mathrm{NH}_{2}$-terminal region upstream of the BIR1 domain of various insect cellular and viral IAPs. Conserved DXXD motifs, Asn residues and BIR1 are boxed. Amino acids with similar properties are colour coded: blue $(\mathrm{F}, \mathrm{W}, \mathrm{Y})$; green $(\mathrm{I}, \mathrm{L}, \mathrm{M}, \mathrm{V})$; red $(\mathrm{H}, \mathrm{K}, \mathrm{R})$; orange $(\mathrm{G}, \mathrm{P}, \mathrm{S}, \mathrm{T})$. Conserved, partially conserved and similar-amino acid residue alignments are marked with an asterisk, full-stop and colon, respectively. For sequence accession numbers see Materials and Methods. (b) Partial evolutionary and phylogenetic relationship of Holometabola insects. Note, the Lepidoptera have not been resolved. Divergence times were from Burmester et al. ${ }^{20,21}$
} 
consistent with the lack of a consensus caspase cleavage site, the viral OpIAP3, CpGV-IAP3 and HcNPV-IAP3 were not cleaved (Supplementary Information Figure 1A).
Next, we tested whether the insect IAPs can stably interact with drICE and DCP-1. TAP-tagged full-length IAPS were expressed in 293T cells, and following TAP purification,

a
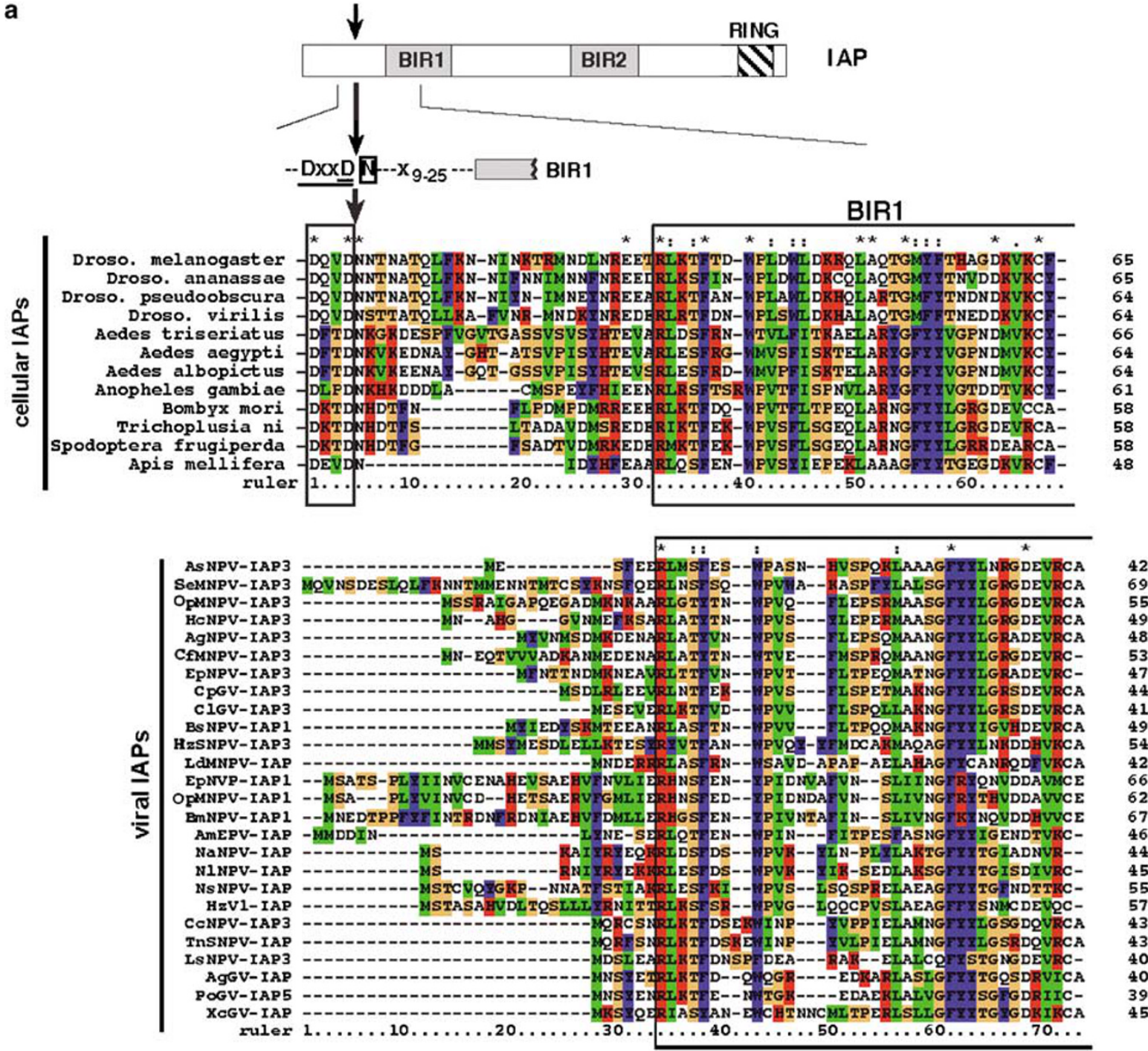

b

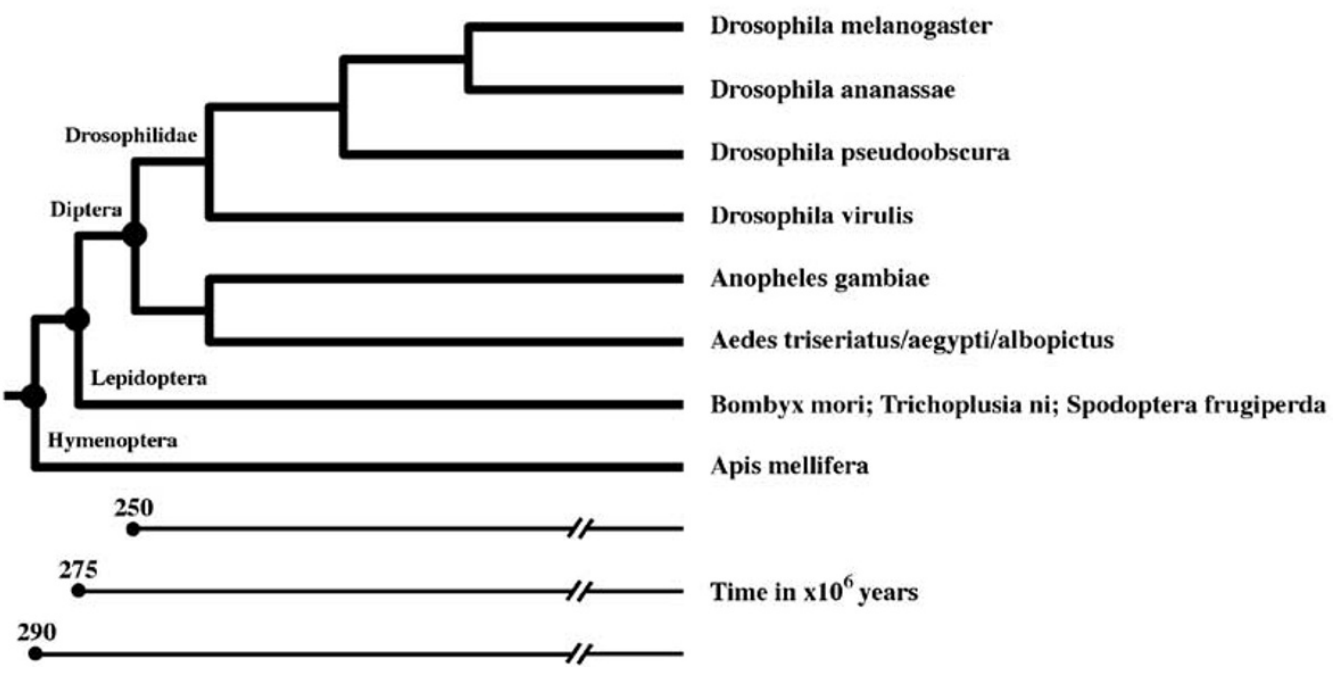


resin-immobilised IAP-TAP were incubated with extracts of cells expressing either drICE or DCP-1. The processed and active form of drICE and DCP-1 was readily co-purified by these IAPs (Figure 2b). By contrast, the viral IAPs OpIAP3, CpGV-IAP3 and HcNPV-IAP3 that lack a DXXD $\downarrow N$ motif (see Figure 1a) and failed to be cleaved (Supplementary Information Figure $1 \mathrm{~A}$ ), also failed to bind to drICE, DCP-1 or effector caspases from $A$. gambiae and $S$. frugiperda $\left({ }^{31}\right.$ and Figure 2b, lane 13 and Supplementary Information Figure $1 \mathrm{~B}$ and $\mathrm{C}$ ). Thus, all IAPs that were cleaved also formed a stable complex with the Drosophila effector caspases drICE and DCP-1. The observation that IAPs from $D$. melanogaster, $A$. gambiae, $A$. aegypti, $B$. mori and $S$. frugiperda are readily cleaved by caspases suggest that the molecular events leading to exposure of the destabilizing residue Asn are conserved among the insect cellular IAPs analysed.
To establish the site of caspase cleavage, we mutated the $\mathrm{P}_{1}$ Asp residue of the putative cleavage site to Ala. In addition, we used species-specific caspases to assess cleavage of their respective IAPs. As with the Drosophila effector caspase DCP-1 and DIAP1 (see Figure 2a), effector caspases from S. frugiperda and A. gambiae cleaved SfIAP and AgIAP3, respectively (Figure $2 c-e$ ). Cleavage occurred at the $\mathrm{DXXD} \downarrow N$ motif as insect IAPs with a mutation in the caspase-cleavage site (DXX므 $>D X X \underline{A}$ ), were fully resistant to caspase-mediated proteolysis (Figure 2c-e, top panel, compare lane 2 with 4). Moreover, ${ }^{20} \mathrm{NK}-\mathrm{AgIAP3}$ and ${ }^{84} \mathrm{NH}-\mathrm{SfIAP}$ fragments, starting at the predicted P1' site, comigrated on SDS Gels with cleaved forms of the respective wild-type counterparts (Supplementary Information Figure 2). SfIAP, AgIAP3 and BmIAP (B. mori) were also cleaved when exposed to apoptotic lysate from Sf9 cells ( $S$. frugiperda),

a

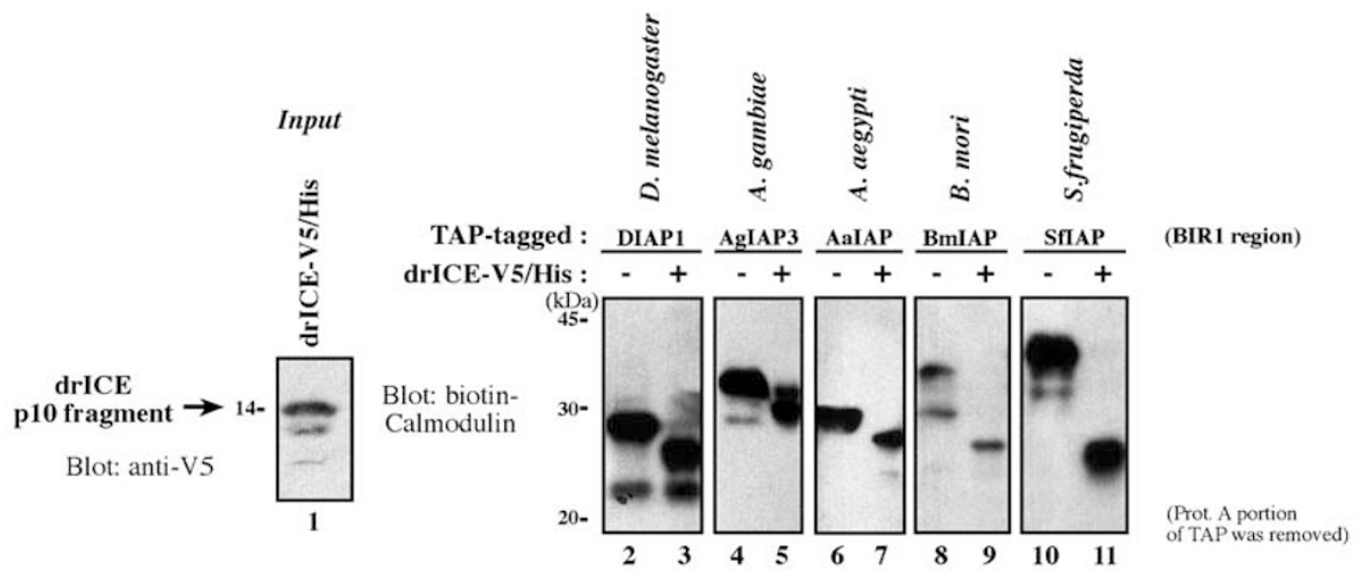

b
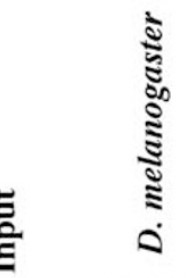

TAP-tagged :

drICE-V5/DCP-1-V5 :

Blot: anti-V5 14- $\stackrel{(\mathrm{kDa})}{\square}$

DIAP1 AgIAP3
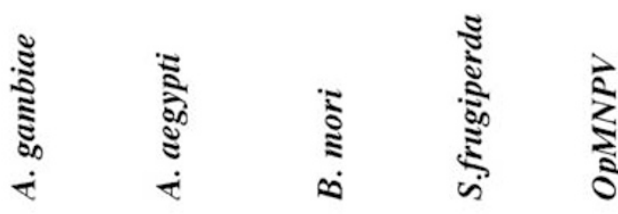

ऐ

อั

Blot: anti-V5
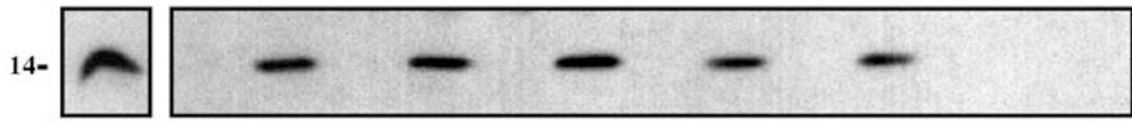

97-

Blot: anti-TAP

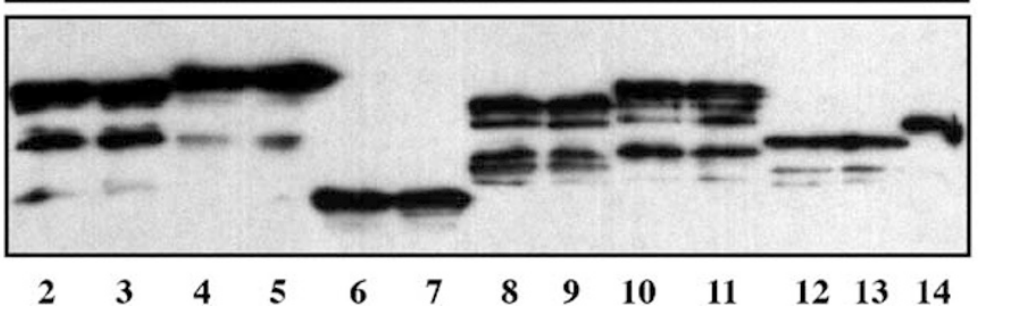

DCP-1

drICE

p10 fragment

p10 fragment

IAPs/

DEP

Figure 2 Continued 
C

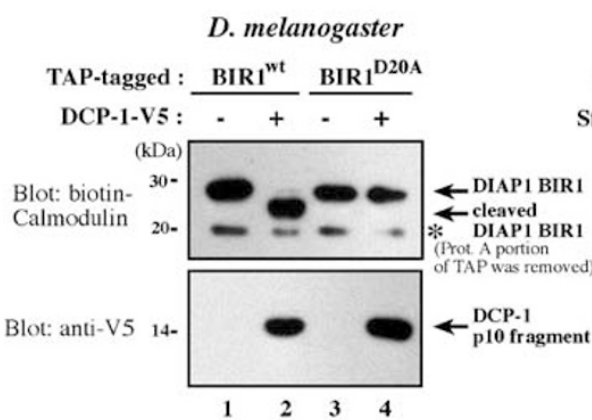

f

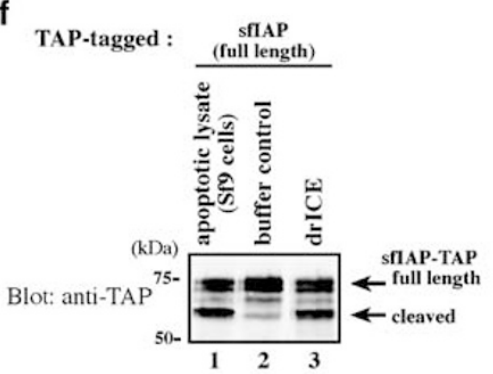

d

Cleavage assay

\section{S. frugiperda}

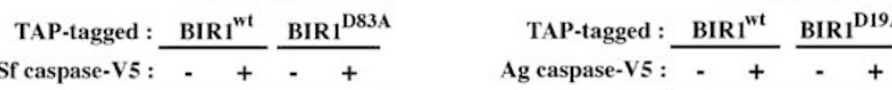

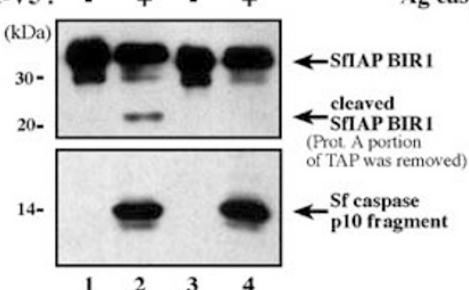

e

Cleavage assay

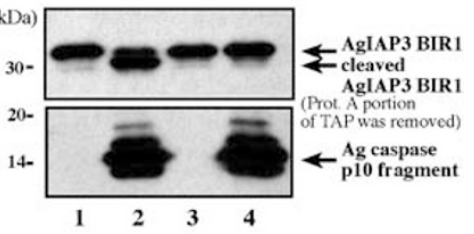

g

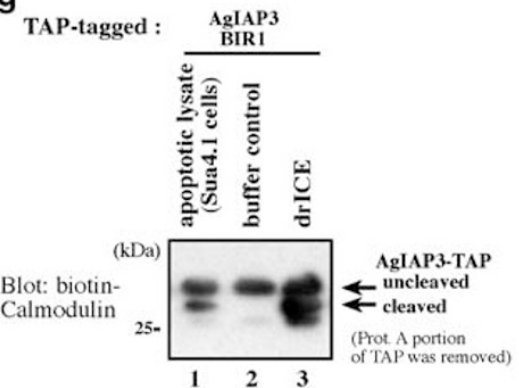

h

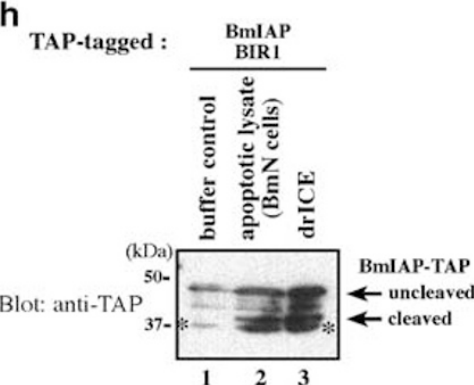

Figure 2 Caspase-mediated cleavage and caspase:IAP-association are evolutionarily conserved across a wide range of Holometabola insects. (a) Cleavage assay, all insect IAPs analysed are cleaved by the Drosophila effector caspase drICE. TAP-tagged IAPs were expressed in 293T cells and purified using tandem affinity purification. Note, the $\mathrm{NH}_{2}$-terminal half of the indicated IAPs (BIR1 region), which includes the caspase cleavage site and the BIR1 domain, was used to help to $\mathrm{NH}_{2}$-terminal cleavage due to its reduced size. Moreover, the Protein A portion of the TAP-tag was removed to further reduce their size. The much larger size difference between full length and cleaved BmIAP and SfIAP, compared to the other IAPs, is owing to a larger $\mathrm{NH}_{2}$-peptide (sequence from the initiating Met to the P1 position of the DXXD motif) of these IAPs. The length of the $\mathrm{NH}_{2}$-peptides are: DIAP1 (20Aa), AgIAP3 (19Aa), AalAP (18Aa), BmIAP (57Aa), SfIAP (83Aa). V5/His-tagged drICE was expressed in 293T cells and purified, using nickel beads, from cellular extracts (left panel, lane 1). Immobilised active drICE was subsequently incubated with the indicated purified IAPs (lanes 2-11) (see Materials and Methods for details). IAPs were monitored using western blot analysis with biotinylated calmodulin, which detects the calmodulin-binding protein of the TAP tag. Purification of active drICE was verified by immunoblot analysis with anti-V5 antibodies. (b) Binding assay (TAP-purification), cellular IAPs stably associate with the Drosophila effector caspases drICE and DCP-1. Note, the viral IAP OpIAP3 (lane 12 and 13) fails to interact with the Drosophila effector caspases drICE and DCP-1. The unrelated tyrosine phosphatase DEP-1 was used as negative control (lane 14). For this binding assay, TAP-tagged proteins were expressed in 293T cells and purified using IgG Sepharose beads. Full-length IAPs were used in this assay, except for AalAP (lanes 6 and 7), for which the $\mathrm{NH}_{2}$-terminal portion (including the BIR1 domain) was used due to difficulties in expressing full-length AalAP. Subsequently, immobilized and purified TAP-tagged proteins were used as affinity reagents to purify the indicated active effector caspase from cellular extracts. Expression of drICE or DCP-1 (lane 1) and their co-purification with the indicated TAP-tagged proteins (lanes 2-14) was determined by immunoblot analysis using the indicated antibodies. Purification of TAP-tagged proteins was verified by immunoblotting with an antibody (anti-TAP) recognising the TAP tag (bottom panel). (c-e) Species-specific caspases cleave their corresponding IAPs at DXXD $\downarrow$ N. Cleavage assay using species-specific caspases and either wild-type or mutant IAPs that carry a single-point mutation in the predicted caspase cleavage site (DXX므 $>\overline{\mathrm{DXX}} \underline{\text { ) }}$. Cleavage site mutant IAPs are fully resistant to caspase-mediated proteolysis indicating that these IAPs are cleaved at the DXXD $\downarrow N$ motif. An asterisk indicates a crossreactive band. Note, the protein A portion of the TAP tag was removed by TEV protease to reduce the size of the BIR1 proteins, facilitating the visualisation of $\mathrm{N}$-terminal cleavage. The cleavage assay was conducted as described in (a). (f-h) SfIAP, AglAP3 and BmIAP are cleaved following exposure to apoptotic lysates from Sua4.1 cells (A. gambiae) (f), Sf9 cells (S. frugiperda) (g) and BmN cells (B. mori) (h). TAPtagged IAP-BIR1 fragments were purified from 293T cells and exposed to apoptotic lysates from species-specific cell lines, or drICE (see Materials and Methods for details). An asterisk indicates a crossreactive band. Note, the protein A portion of the TAP tag was removed for $(\mathbf{g})$ to reduce the size of the BIR1 protein, facilitating the visualisation of $\mathrm{N}$-terminal cleavage

Sua4.1 cells ( $A$. gambiae) and $\mathrm{BmN}$ cells (B. mori), respectively (Figure $2 f-h$ ). This suggests that caspasemediated cleavage of these IAPs occurs in these species.

Effector caspases need to bind to the BIR1 before IAP cleavage at the DXXD $\downarrow \mathbf{N}$ motif. In vitro binding of drICE to DIAP1 has been reported to occur only after the cleavage and removal of DIAP1's $\mathrm{NH}_{2}$-terminal 20 amino-acid residues. ${ }^{17}$ Accordingly, full-length, non-cleaved DIAP1 was postulated to reside in an auto-inhibited state that precludes binding to effector caspases, and that binding would only occur once this region is cleaved off. This is an attractive model that might help to explain why the DXXD $\downarrow N$ motif is evolutionarily conserved. To test this we examined whether cleavage and removal of their $\mathrm{NH}_{2}$-terminal amino acids is required for caspase binding. However, we found that noncleavable, IAP BIR1-regions co-purified catalytically active caspases from cellular extracts. These non-cleavable $I A P^{D>A}$ mutants bound to effector caspases as efficiently as their wild-type counterparts (Figure $3 a-c$, top panel, compare lane 3 with 5 ). This indicates that the caspase cleavage site, or indeed cleavage itself, was not required for caspase binding. Moreover, these data show that loss of IAP cleavage was due to mutation of the caspase cleavage site and not due to defective caspase-binding.

As IAP cleavage was not required for caspase binding, we examined whether cleavage occurred only after binding of the caspase to the BIR domain. Generally, caspases recognise 


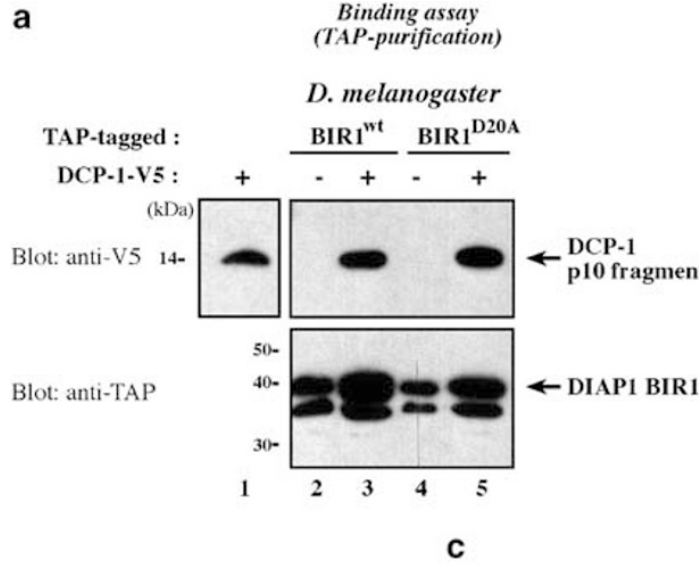

b

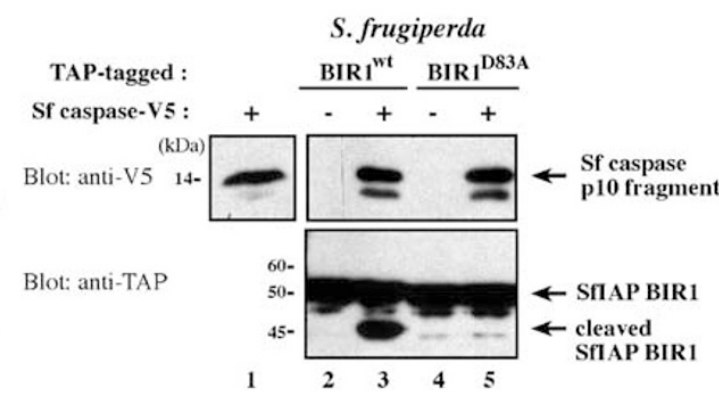

Binding assay

(TAP-purification)

A. gambiae

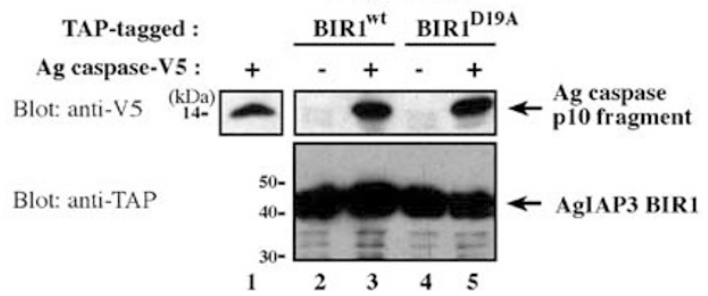

Figure $3 \mathrm{NH}_{2}$-terminal cleavage is not required for IAP-binding. (a-c) Binding assay with species-specific caspases and either wild-type or cleavage-site mutant IAPs. Both wild-type and $D>A$ mutant IAP fragments readily co-purified their respective caspase from cellular extracts indicating that cleavage is not required for binding. For this assay, we used the $\mathrm{NH}_{2}$-terminal half of the indicated IAPs (BIR1 region). The binding assay with purified and immobilised TAP-tagged IAP fragments was conducted as described in Figure $2 b$

substrates via the cleavage motif, whereby this region directly interacts with the catalytically active pocket of the caspase. In the case of insect IAPs, however, caspases bind to two protein surfaces: the DXXD $\downarrow N$ motif as well as the BIR domain. We, therefore, determined the contribution of the BIR domain for IAP cleavage. To this end, we tested whether catalytically competent caspases could cleave IAPs independent of their binding to the BIR1 domain. We introduced Cys to Gly mutations in the BIR1 domains to abolish BIR1-mediated binding. Mutation of Cys80 to Gly in DIAP1's BIR1 domain has previously been shown to abrogate binding and cleavage by drICE and DCP-1. ${ }^{16}$ Corresponding mutations in the BIR1 domain of SfIAP-BIR1 ${ }^{\mathrm{C} 139 \mathrm{G}}$ and AgIAP3-BIR1 ${ }^{\mathrm{C} 102 \mathrm{G}}$ similarly abrogated the binding to their respective effector caspases (Figure 4a and b). Although wild-type SfIAP and AgIAP3 were efficiently cleaved by the effector caspases from $S$. frugiperda and $A$. gambiae, respectively, BIR $1^{\mathrm{C}>\mathrm{G}}$ mutant IAPS, which failed to interact with caspases, also failed to be cleaved (Figure 4c and d, top panel, compare lanes 2-4 with lanes 6-8). Even over a longer time period, SfIAP-BIR1 ${ }^{\mathrm{C} 139 \mathrm{G}}$ and AglAP3-BIR1 ${ }^{\text {C102G }}$ were significantly refractory to caspasemediated cleavage (compare lane 4 with 8 ). The notion that IAP cleavage depends on BIR-binding indicates that IAPs behave not like normal caspase substrates, which merely rely on the cleavage motif for proteolysis. Collectively these data indicate that, following caspase binding, IAPs from $D$. melanogaster, $S$. frugiperda and $A$. gambiae are cleaved at equivalent positions $\mathrm{NH}_{2}$-terminal to their BIR1 domains.
N-end-rule-mediated IAP degradation. Caspase-mediated cleavage of DIAP1 at position 20 converts the more stable full-length DIAP1 into the highly unstable Asn-degronbearing DIAP1. Exposure of the neo- $\mathrm{NH}_{2}$-terminus results in the recruitment of an unknown $\mathrm{N}$-end-rule-specific E3 ligase, which in turn targets DIAP1 for proteasomal degradation. ${ }^{15}$ To assess whether the molecular consequence of cleavage, namely exposure of a destabilising residue and corresponding instability, is conserved across species we compared the expression levels of IAPs bearing different $\mathrm{NH}_{2}$-terminal residues. Using the Ub-fusion technique, ${ }^{32,33}$ we expressed $\mathrm{SflAP}^{\mathrm{N} \text {-degron }}$ and SflAP ${ }^{\mathrm{M} \text {-degron }}$ that carries a stabilising Met residue $(\mathrm{M})$, instead of $A s n(\mathrm{~N})$, at its neo $\mathrm{NH}_{2}$-terminus. The Ub-fusion technique, in which a Ub reporter is fused to the test protein allows the expression of the test protein initiating with the desired residue (Figure 5a). De-ubiquitinating proteases (DUBs) co-translationally cleave these fusion proteins at the C-terminus of the Ub moiety, ${ }^{32,33}$ yielding the test protein $I A P^{N-\text { degron }}$ or $I A P^{M-d e g r o n}$. By comparison, $D m$ and $S f I A P^{\mathrm{M} \text {-degrons }}$ were expressed to a significantly higher level than their IAP ${ }^{\mathrm{N} \text {-degron }}$ counterparts, which were barely detectable (Figure $5 b$ and $c$ ). Addition of the proteasome inhibitor lactacystin increased the levels of DIAP1 ${ }^{\mathrm{N} \text {-degron }}$ and $\mathrm{SfIAP}{ }^{\mathrm{N} \text {-degron }}$ lactacystin treatment also affected the levels of DIAP1 ${ }^{\mathrm{M} \text {-degron }}$ and SfIAP ${ }^{\mathrm{M} \text {-degron }}$ consistent with the notion that NERD- and RING-finger activities influence IAP protein levels. These results demonstrate that, relative to the Met-degron-bearing IAPS, Asn-degron-bearing IAP protein levels were reduced, and 
a

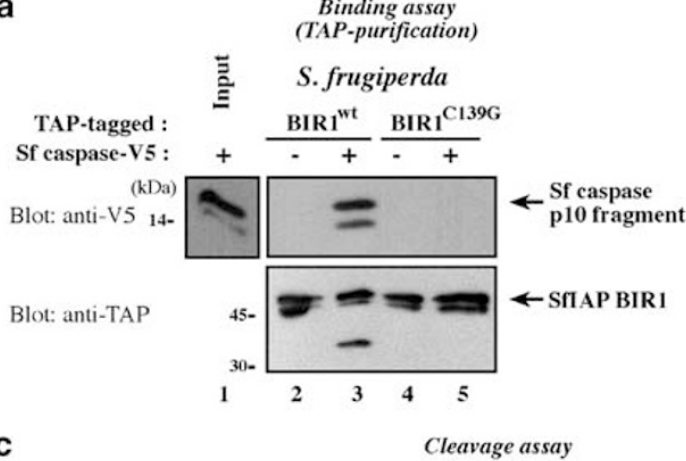

C

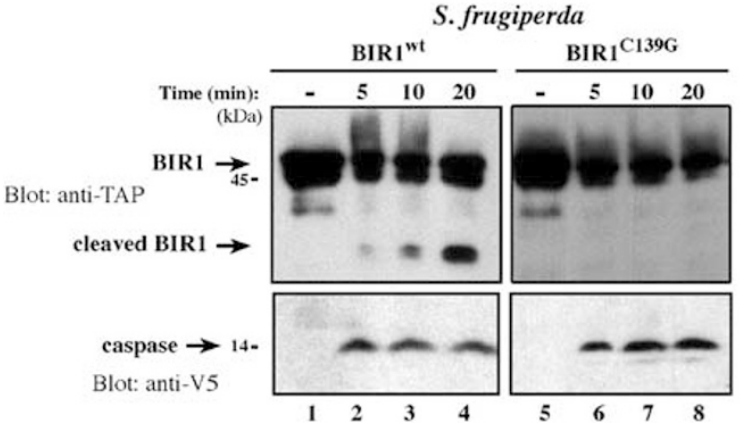

b

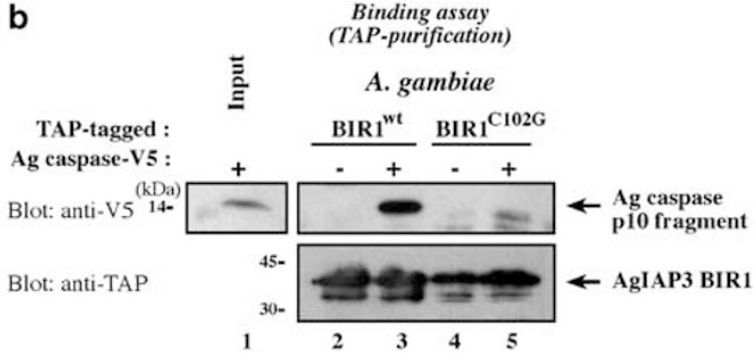

d

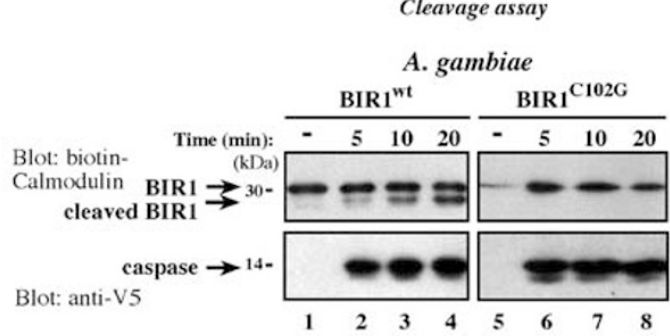

Figure 4 Caspases that fail to localise to the BIR1 domain also fail to cleave the IAP at the DXXD $\downarrow N$ motif. (a and $\mathbf{b})$ Cys to Gly mutation at the indicated position in the BIR1 domain of SfIAP (a) and AgIAP3 (b) abrogates caspase binding. Purified TAP-tagged IAP fragments (BIR1 region) were used as affinity reagents to co-purify their corresponding caspases from cellular extracts. The binding assay was conducted as in Figure $2 \mathrm{~b}$. (c and $\mathbf{d}$ ) Time course analysis of the indicated cleavage assay. Although wild-type SfIAP and AgIAP3 were efficiently cleaved by their respective effector caspases, BIR1 ${ }^{\mathrm{C}>\mathrm{G}}$ mutant IAPs, which failed to interact with caspases, also failed to be cleaved (top panel, compare lanes $2-4$ with lanes $6-8$ ). Even over a longer time period, SfIAP-BIR1 ${ }^{\mathrm{C} 139 \mathrm{G}}$ and AgIAP3-BIR1 ${ }^{\mathrm{C} 102 \mathrm{G}}$ were significantly refractory to caspasemediated cleavage. The cleavage assay was conducted as described in Figure 2a. Note, the protein A portion of the TAP tag was removed for (d) to reduce the size of the BIR1 protein, facilitating the visualisation of $\mathrm{N}$-terminal cleavage

that the observed reduction is due to the ubiquitin-proteasome system.

N-end rule's role in regulating IAPs' antiapoptotic efficacy. We next examined the functional consequence of $\mathrm{N}$-end-rule-mediated degradation of insect cellular IAPs. To address this, we performed cell-based killing assays in Drosophila cells (S2). Induced expression of the IAP. antagonist Reaper (Rpr) in S2 cells triggers apoptosis that is predominantly executed by the effector caspase drICE. ${ }^{34-36}$ We have used this system to reveal whether exposure of the $\mathrm{N}$-degron contributes to the antiapoptotic potential of insect IAPs. When compared to their wild-type counterparts, all non-cleavable, full-length $I A P^{D>A}$ mutants were significantly impaired in their ability to suppress apoptosis, with an average reduction of $56 \%$ below the levels of their wild-type forms (Figure $5 \mathrm{~d}$ ). Furthermore, IAPs that exposed a stabilising M-degron were consistently worse at suppressing apoptosis than those with a destabilising $\mathrm{N}$-degron, with an average decrease of $35 \%$ below the levels of their $\mathrm{N}$-degron counterparts (Figure $5 \mathrm{e}$ ). The enhanced protective effect of $I \mathrm{AP}^{\mathrm{N} \text {-degrons }}$ was blunted when Ate-1 and Ntan-1, two components of the NERD pathway, were knocked down by RNAi, with an average difference of $8 \%$ (Figure $5 f$ ). These sets of results demonstrate that exposure of a destabilising $\mathrm{N}$-degron and engagement of the NERD-pathway contributes to the antiapoptotic potential of insect IAPs. Impairment of $\mathrm{N}$-end-rule-mediated degradation of IAPs, either through (1) blocking caspase-mediated cleavage and exposure of the $\mathrm{N}$-degron $(\mathrm{D}>\mathrm{A}),(2)$ mutation of the $\mathrm{N}$-degron's $\mathrm{NH}_{2}$-terminal amino acid $(\mathrm{N}>\mathrm{M})$, or (3) RNAi-mediated knock down of components of the NERD pathway, attenuates the IAPs' protective function. Overall, both SfIAP and AgIAP3 seem to utilise an evolutionarily conserved $\mathrm{N}$-end-rule-associated mechanism to regulate apoptosis.

Next we wished to reveal whether DIAP $1^{\mathrm{N} \text {-degron }}$ was selectively acting through inhibiting associated effector caspases, or alternatively, whether it blocked cell death by neutralising Rpr or DRONC. To this end, we used a $t h^{11-3 e}$ mutant of DIAP1 $1^{\mathrm{N} \text {-degron }}\left(\mathrm{DIAP} 1^{11-3 e / \mathrm{N} \text {-degron }}\right) . t h^{11-3 e}$ is a loss-of-function allele of DIAP1 that carries an Asn to Lys mutation at position 117, immediately C-terminal to the BIR1 domain. ${ }^{5}$ This mutation selectively abrogates DIAP1's ability to associate with drICE and DCP-1. Importantly, this mutation does not affect DIAP1's ability to interact with Rpr/Grim/Hid or DRONC. $^{37}$ Interestingly, DIAP1 ${ }^{11-3 e / N-d e g r o n}$ was impaired in its antiapoptotic activity (Figure $5 \mathrm{~g}$ ). Thus, despite its normal binding to Rpr and DRONC, DIAP1 ${ }^{11-3 e / N-d e g r o n}$ failed to thwart Rpr killing. Hence, it seems that loss of effector caspase binding, through the 11-3e mutation, negates the antiapoptotic ability of DIAP1 ${ }^{\mathrm{N} \text {-degron }}$ Taken together these data indicate that the $\mathrm{N}$-end-rule-associated mechanism neutralises effector caspases. 


\section{Discussion}

Recent efforts to sequence the entire genomes of a number of insect species, has allowed analysis of genomic sequences spanning 290 million years of evolution. ${ }^{20}$ Across the wide range of insect IAPs examined, we noticed evolutionary conservation of the DXXD $\downarrow N$ motif, in addition to the BIR and RING domains, highlighting its evolutionary and functional significance. Our results demonstrate that whereas the
$\mathrm{DXXD} \downarrow N$ motif does not contribute to effector caspase binding, it is required to neutralise effector caspases and suppress cell death. Following binding of the caspase to the BIR1 domain, insect IAPs are cleaved at this motif exposing a destabilizing residue of the $\mathrm{N}$-end rule that plays an important role for their full antiapoptotic potential. This is evident because non-cleavable mutant forms of IAPs, or IAP ${ }^{\mathrm{M} \text {-degrons }}$ that expose a stabilizing Met residue, fail to block cell death effectively. It is noteworthy to indicate that the effector a reference protein

\begin{tabular}{|l|r|r|}
\hline UB $-\mathrm{X}-$ & \multicolumn{3}{c}{ test protein } \\
\hline & BIR1 & BIR2 \\
\hline
\end{tabular}

DIAP1 $\downarrow$ DUBs

UB

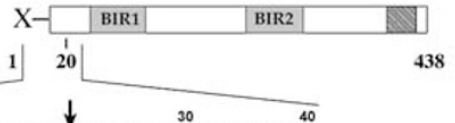

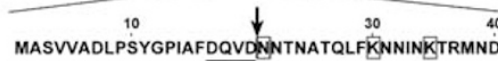

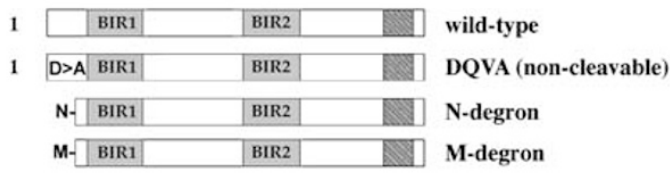

b

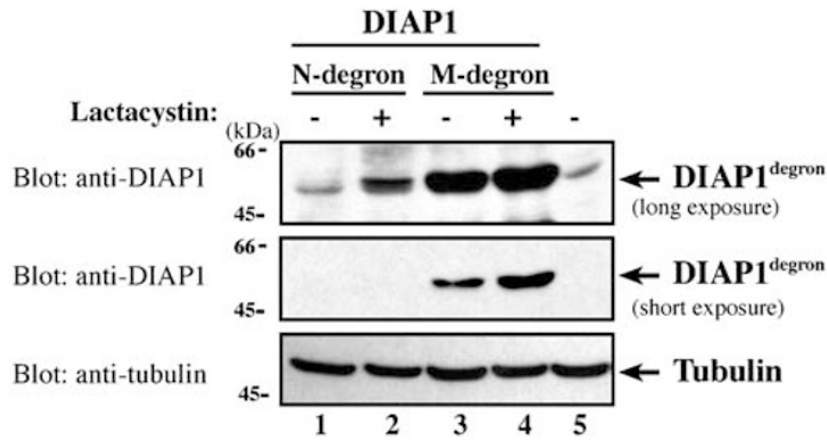

C

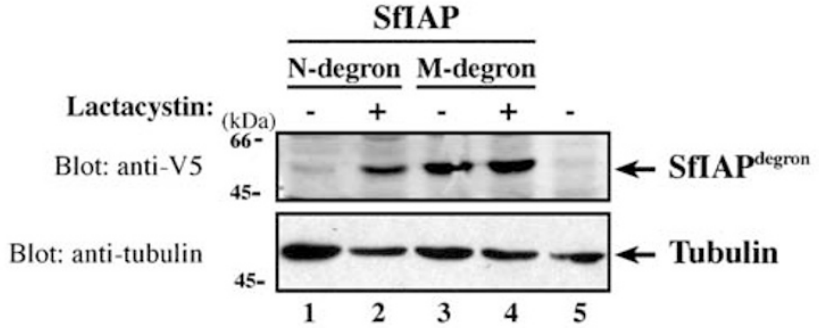

d
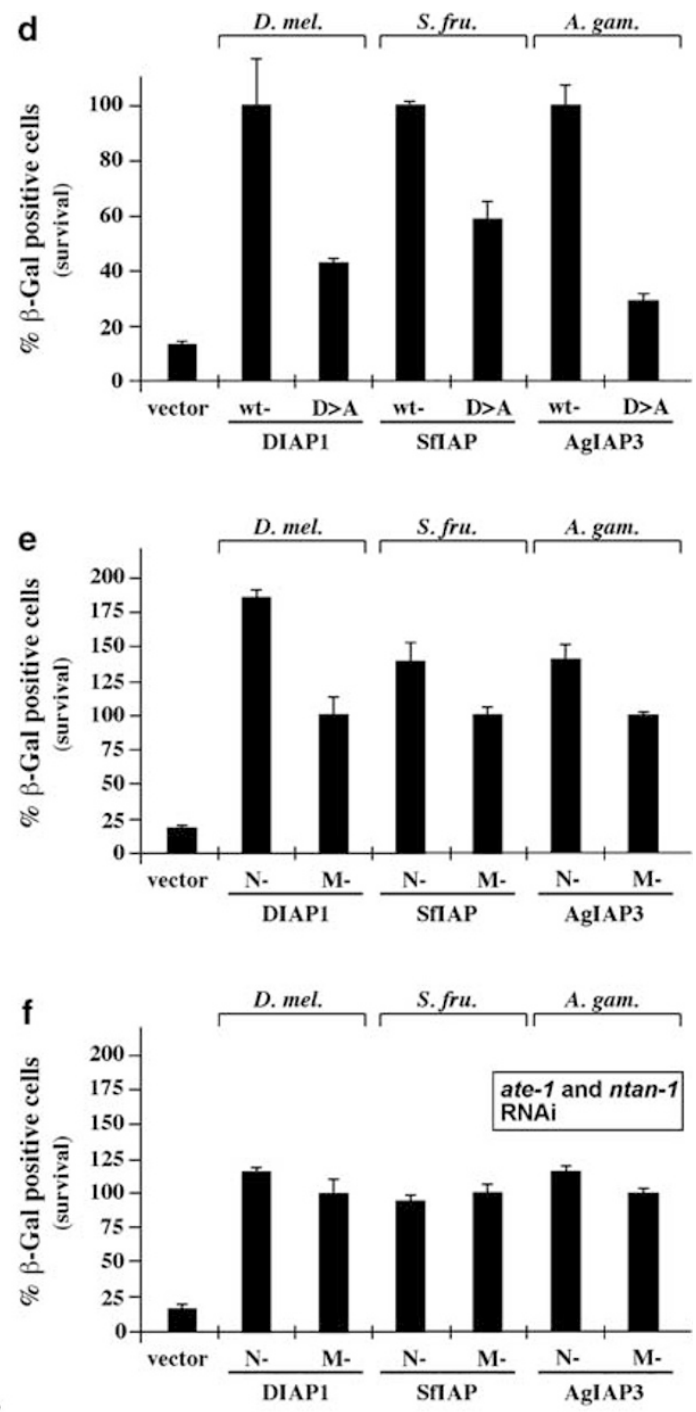

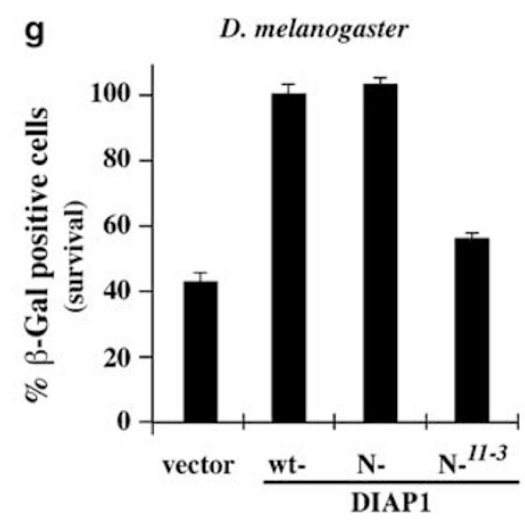


caspases drICE and DCP-1 bind to the BIR1 through an IAPbinding motif present at the $\mathrm{NH}_{2}$-terminal portion of the $\mathrm{p} 20$ large caspase subunit, which is exposed following caspase activation. $^{16}$ Therefore, the BIR1 provides the caspase with an IAP-docking site that localises the caspase to its cleavage site. Of the insect IAPs examined, spatial retention of the DXXD $\downarrow N$ motif nine-25 amino acids $\mathrm{NH}_{2}$-terminal to the BIR1 domains permits BIR1-directed caspase-mediated IAP cleavage.

Although caspase:IAP binding is essential for caspase inhibition, association alone is not sufficient. In the case of the insect IAPs examined, caspase-mediated cleavage is required to activate their full antiapoptotic potential. In this respect, effector caspases trigger their own inhibition by cleaving and activating their own inhibitors - the IAPS. Cleavage of the IAPs' $\mathrm{NH}_{2}$-termini exposes Asn, a destabilising residue of the $\mathrm{N}$-end rule. Failure to expose this residue, either through mutation of the DXX $\underline{D}$ cleavage site or substitution of the destabilizing Asn residue to a stabilizing Met residue, reduces the IAPs' antiapoptotic potency. Although the functional consequence of Asn exposure results in cell-death inhibition, the underlying biochemical mechanism remains somewhat elusive. It seems that Asn-exposure results in the recruitment of $\mathrm{N}$-end-rule-specific E3 ligase(s) to the IAP:caspase complex. According to this scenario, once localised to this complex, the $\mathrm{N}$-end rule E3:E2 machinery ubiquitylates both DIAP1 and the associated active effector caspases. Accordingly, the IAP ${ }^{\mathrm{N} \text {-degron }}$ may function as a scaffold or adaptor that recruits the $\mathrm{N}$-end rule E3:E2 machinery into the vicinity of active effector caspases. Although it is clear that DIAP1-mediated recruitment of the $\mathrm{N}$-end rule machinery results in DIAP1 degradation and suppression of apoptosis, technical difficulties have so far precluded biochemical insights into how effector caspases are neutralized. A key problem is the generation of detectable levels of active effector caspases without causing apoptosis and concomitant loss of cellular material. Attempts to sustain cell viability, through exposure to pharmacological or viral apoptosis inhibitors, also intrinsically interfere with either caspase activation/activity or IAP: caspase association. Nevertheless, whatever the biochemical mechanism, cleavage of IAPs causes their degradation, which in turn results in the protection against caspasemediated death.
Through exposure of the IAPs' N-degron, insect IAPs appear to recruit the ubiquitylation machinery of the NERD pathway, which causes their proteasome-dependent degradation. Failure to engage the NERD pathway leads to increased IAP expression, but decreased antiapoptotic activity. This view is supported by the observation that RNAi-mediated knock down of Ate-1 and Ntan-1, two essential components of the NERD-pathway, significantly impairs the antiapoptotic potency of IAP ${ }^{\mathrm{N} \text {-degrons }}$ (see Figure 5f). Therefore, it seems that the instability of insect IAPs may act as an indirect indicator for their antiapoptotic activity. Similarly, increased IAP expression, but decreased antiapoptotic activity is also seen with DIAP1 RING mutants that are defective in DRONC ubiquitylation. ${ }^{6}$ Hence, DIAP1's two ubiquitylation-associated activities (NERD and RING) contribute to its antiapoptotic ability, but at the expense of the protein's stability. Preliminary experiments indicate that RING mutation reverses the DIAP1 ${ }^{\mathrm{N} \text {-degron }}$-mediated protection against Rpr killing ( ${ }^{19}$ and unpublished observations, MD and $P M$ ) suggesting that functionally the RING finger overrides the NERD pathway. From this perspective the NERD pathway needs a functional RING to manifest an antiapoptotic effect. However, when DIAP1 has a functional RING, but is impaired for the NERD pathway, as with either DIAP1 ${ }^{\text {DQVA }}$ or DIAP1 ${ }^{\mathrm{M} \text {-degron }}$ (see Figure $5 \mathrm{~d}$ and e), it alone cannot protect either. And in this setting a defective NERD pathway overrides the antiapoptotic activity of a functional RING. Therefore, both DIAP1's N-end-rule- and RING-mediated antiapoptotic mechanisms seem, from an antiapoptotic viewpoint, interdependent and equally important. A possible explanation for the functional requirement of the two ubiquitin-associated processes (NERD and RING) may be based on DIAP1's role to synchronously neutralise initiator and effector caspases. DIAP1 BIR mutations that selectively abrogate binding to either initiator $\left(\right.$ diap $1^{\text {th }}$ ) or effector caspases (diap $1^{11-3 e}$ ) causes loss of DIAP1 function resulting in lethality. Thus, DIAP1 needs to regulate both initiator and effector caspases to block apoptosis. Inhibition of either caspase class alone is insufficient to sustain viability. Hence, overall our results support a model for two separate IAP-mediated ubiquitylationassociated mechanisms for regulating initiator and effector caspases.

Recent discoveries are beginning to reveal mechanistic differences in the way IAPs inhibit caspases, which may have

Figure $5 \quad \mathrm{NH}_{2}$-terminal cleavage and exposure of the destabilising residue Asn renders insect IAPs unstable and is required for their ability to protect against cell death. (a) Schematic representation of the Ub-fusion technique and the IAP N-end-rule mutants used in this study. DUBs indicates de-ubiquitinating proteases. (b and $\mathbf{c}$ ) Overall protein levels of DIAP1 $1^{\mathrm{N} \text {-degron }}(\mathbf{b})$ and $\operatorname{SfIAP}^{\mathrm{N} \text {-degron }}(\mathbf{c})$ are increased upon mutation of the $\mathrm{N}$-end rule's destabilising Asn residue to the stabilising residue Met. DIAP1 $1^{\mathrm{N} \text {-degron }}$ and SfIAP ${ }^{N-d e g r o n}$ were expressed using the Ub-fusion technique using mammalian RAT1 cells. Mammalian cells were used to avoid interference by endogenous DIAP1. Addition of the proteasome inhibitor, lactacystin, increases the expression level of unstable IAP ${ }^{\mathrm{N} \text {-degrons }}$ Moreover, it also affects IAP ${ }^{\mathrm{M} \text {-degrons }}$ consistent with the notion that the NERD- and RING-finger activities both influence IAP levels. (d-g) Rpr-mediated killing assays in Drosophila S2 cells (see Materials and Methods). (d) Expression of Rpr in Drosophila S2 cells results in rapid induction of cell death, which is efficiently blocked by co-expression of wild-type IAPs but not by non-cleavable IAP mutants. The efficiency with which wild-type IAPs suppress Rpr killing was arbitrarily set as $100 \%$ and the efficiency of non-cleavable, full-length IAP mutants was expressed in relation to their wildtype counterparts. Constructs encoding the indicated IAPs were co-tansfected together with Rpr and the reporter plasmid pIE1-3- $\beta$-galactosidase. $24 \mathrm{~h}$ post-transfection, cells were fixed and stained for LacZ activity and the number of blue cells were counted as an indicator of cell survival. Differences in transfection efficiencies were normalised by using Z-VAD-fmk-treated controls. (e) IAPs that expose a destabilizing residue of the $\mathrm{N}$-end rule (IAP ${ }^{\mathrm{N} \text {-degrons }}$ ) are significantly more efficient in blocking Rpr killing than M-degron bearing IAPs (IAP $\left.{ }^{M-d e g r o n s}\right)$. The efficiency of IAP ${ }^{M-d e g r o n s}$ was set as $100 \%$ and the one of IAP ${ }^{N \text {-degrons }}$ was expressed in relation to their M-degron counterparts. (f) The protective effect of IAP ${ }^{\mathrm{N} \text {-degrons }}$ was reduced when Ate-1 and Ntan-1 were knocked down by RNAi, with an average difference between IAP $P^{\mathrm{N}-\text { degrons }}$ and IAP ${ }^{\mathrm{M}-\text { degrons }}$ of $8 \%$. The efficiency of IAP ${ }^{M-d e g r o n s}$ was set to $100 \%$ and the one of IAP ${ }^{N \text {-degrons }}$ was expressed in relation to their M-degron counterparts. (g) The th ${ }^{11-3 e}$ DIAP1 mutation, which selectively ablates binding of effector caspases to DIAP1, but does not interfere with Rpr/Grim/Hid or Dronc binding, negates the antiapoptotic activity of DIAP1 $1^{\mathrm{N}-\text { degron }}$ This indicates that the $\mathrm{N}$-end-rule-associated mechanism neutralizes effector caspases. Error bars represent standard deviations derived from triplicate experiments 
important implications in the design of therapeutic compounds. Although the ultimate outcome of IAP activity seems to be the same, namely the prevention of apoptosis, alternative strategies may be used to achieve the same goal. This hypothesis may be supported by the observation that certain IAPs, such as the insect viral IAPs OpIAP3, CpGVIAP3 and HCNPV-IAP3, potently suppress virus-induced apoptosis of infected cells even though they fail to associate with effector caspases such as drICE, Ag-caspase and Sf-caspase ( ${ }^{31}$ and this study). As we have only tested a small number of caspases and viral IAPs, it is possible that OpIAP3, CpGV-IAP3 and HcNPV-IAP3 (or other insect virus IAPs) may interact with caspases other than the ones we have tested in this study. Nonetheless, viral IAPs seem to lack the motifs required for recruiting the NERD machinery, reinforcing the idea that viral IAPs act as decoy IAPs that neutralise IAPantagonists, ${ }^{38,39}$ rather than caspases, ${ }^{40}$ or block apoptosis by an unknown mechanism. By contrast, cellular insect IAPs with two BIR domains and a C-terminal RING finger readily neutralise caspases. The requirement for caspase-directed activation of the antiapoptotic activity of such insect IAPs provides cells with an efficient strategy to 'sense' and neutralize low levels of active effector caspases.

\section{Note added in Proof}

Recent findings by Herman-Bachinsky et al (Cell Death Differ 2007 Jan 5; E-pub ahead of print) support our previous findings regarding the role of the $\mathrm{N}$-end Rule pathway in degrading DIAP1.

\begin{abstract}
Materials and Methods
Constructs and sequence analysis. Constructs for expression in mammalian cells were generated using PCR-based approaches and cloned into pcDNA3-TAP or pcDNA3-V5/His vectors. Constructs were verified by DNA sequencing. Anopheles cDNAs were cloned from Sua4.1 and 4a-2 cells using RT-PCR. Easy-A $A^{\mathrm{TM}}$ High-Fidelity polymerase (Stratagene, La Jolla, CA, USA) and Reverse transcriptase (Roche, Switzerland) were used. For , C-terminally Myc/Histagged DIAP1 and V5/His-tagged SfIAP and AgIAP3 were used. Mutant IAPs were generated using site-directed mutagenesis with Pfu Turbo polymerase (Stratagene) and cloned into either pcDNA3.1 or pAc5.1 (Invitrogen, Carlsbad, CA, USA). $\mathrm{Ub}-\mathrm{IAP} \mathrm{P}^{\mathrm{N} \text {-degron }}$ and -IAPM-degron fusion constructs were generated by PCR using Expand High Fidelity (Roche, Switzerland) and cloned into either pcDNA3.1 or pAc5.1. IAP sequences were analysed by ClustalX: ${ }^{41,42}$ D. melanogaster AAC41609; D. ananassae danalscaffold 13337; D. pseudoobscura EAL30773; D. virilis dvirlscaffold 13049; A. triseriatus AAL46972; A. aegypti AAS66751; A. albopictus AAL92171; A. gambiae EAA04309; B. mori AAN46650; T. ni AAF19819; S. frugiperda AAF35285; A. mellifera XM396370; AcMNPV NP054056; BmNPV IAP1 AAQ05892; OpMNPV OpIAP1 NP046197; OpIAP3 NP046191; CpGV IAP3 NP14880; AMVIAP NP064803; HcNPV-IAP3 BAC55952; AgNPV-IAP3 AAS92269; EpNPV-IAP3 AAD53953; CfMNPV-IAP3 NP848342; BsNPV-IAP1 AAC34373; CIGV-IAP3 NP891863; AmEPV-IAP NP064803; HzSNPV-IAP3 NP542729; AsNPV-IAP3 YP529789; SeMNPV-IAP3 NP037870; LSNPV-IAP3 YP758337; NaNPV-IAP YP667869; NINPV-IAP YP025208; CcNPVIAP3 YP249643; TnSNPV-IAP YP308925; XcGV-IAP NP059285; HzV1-IAP NP690554; NsNPV-IAP YP025124; AgGV-IAP YP006238; LdMNPV-IAP NP047776; PoGV-IAP5 NP663273; EpNVP-IAP1 NP203202.
\end{abstract}

Co-purification assays and immunoblot analysis. Co-IP and Western blot analysis were performed essentially as described previously. ${ }^{15,16}$ Briefly, to purify TAP (Protein A/Calmodulin-binding protein)-tagged proteins, 293T cells $\left(2.5 \times 10^{5} \mathrm{cells} / \mathrm{ml}\right)$ were seeded on six-well plates and transiently transfected with $2 \mu \mathrm{g} /$ well of the indicated plasmids using Effectene ${ }^{\circledR}$ (Qiagen, Valencia, CA, USA). $48 \mathrm{~h}$ post-transfection, cells were lysed in $1 \%$ Triton buffer $(50 \mathrm{mM}$ Tris $\mathrm{pH}$
$7.5,150 \mathrm{mM} \mathrm{NaCl}, 1 \%$ Triton X-100, 10\% Glycerol, 1 mM EDTA supplemented with Complete $^{\mathrm{TM}}$ protease inhibitors (Roche)). Crude extracts were centrifuged at $16000 \mathrm{~g}$ for $10 \mathrm{~min}$. and supernatants were incubated for $1 \mathrm{~h}$ with IgG-coupledsepharose beads (first step of TAP-purification scheme, Amersham Biosciences, Piscataway, NJ, USA). Subsequently, IgG beads were washed three times with IPPG150 wash buffer ( $0.1 \%$ Triton, $50 \mathrm{mM}$ Tris pH 7.5, $150 \mathrm{mM} \mathrm{NaCl}, 5 \%$ Glycerol). To assess IAP binding, purified and immobilised IAPs were incubated for $1 \mathrm{~h}$ with cell lysates of 293T cells expressing V5/His-tagged effector caspases. Following three washing steps with IPPG150, bound proteins were eluted with $0.5 \%$ SDS containing wash buffer. IAP-bound samples were washed and examined by immunoblot analysis using chemiluminescence (Amersham Biosciences). The following antibodies were used: anti-V5 (Serotec, Oxford, UK), anti-tubulin (SigmaAldrich, Poole, UK), anti-DIAP1 ${ }^{6}$ anti-TAP was anti-PME (primary rabbit antibody). Where the Protein A portion was removed by TEV cleavage, the TAP-tag was detected using biotinylated Calmodulin (Calbiochem, San Diego, CA, USA).

Cleavage assays. For IAP-cleavage assays, TAP-tagged (Protein A-TEVprotease cleavage site-Calmodulin-binding protein) proteins were purified using tandem affinity purification, ${ }^{30}$ which results in the abscission of Protein A from the TAP-tag. Briefly, TAP-tagged IAPs were purified from 293T cellular extracts using IgG Sepharose beads (Amersham Biosciences) as described above. Following three washes with IPPG150 buffer IgG-immobilised TAP-tagged proteins were incubated for $4 \mathrm{~h}$ with $50 \mathrm{U}$ of TEV protease in TEV cleavage buffer (Invitrogen) to remove the Protein A portion of the TAP-tag. Subsequently, the cleaved proteins were incubated for $1 \mathrm{~h}$ with Calmodulin Sepharose 4B (Amersham Biosciences) in the presence of calmodulin-binding buffer $(0.1 \%$ Triton, $50 \mathrm{mM}$ Tris pH 7.5, $150 \mathrm{mM}$ $\mathrm{NaCl}, 1 \mathrm{mM}$ magnesium acetate, $1 \mathrm{mM}$ imidazole, $2 \mathrm{mM} \mathrm{CaCl}$, $5 \%$ Glycerol). Following three washing steps purified IAP proteins were eluted with calmodulin elution buffer ( $0.1 \%$ Triton, $50 \mathrm{mM}$ Tris $\mathrm{pH} 7.5,150 \mathrm{mM} \mathrm{NaCl}, 1 \mathrm{mM}$ magnesium acetate, $1 \mathrm{mM}$ imidazole, $2 \mathrm{mM}$ EGTA, $5 \%$ Glycerol) and exposed to purified and immobilised active caspases. Purified, active caspases were obtained from cellular extracts of 293T cells. The concentration of the caspases and IAPs range between $10 \mathrm{pg}$ and $1 \mathrm{ng}$. Briefly, 293T cells expressing the indicated caspases were lysed in $1 \%$ Triton buffer and purified using nickel beads according to the manufacturer's instructions (Qiagen). Subsequently, purified IAPs were added to immobilized caspases and incubated for $1 \mathrm{~h}$ at room temperature in reaction buffer $(0.1 \%$ Triton, $50 \mathrm{mM}$ Tris pH 7.5, $150 \mathrm{mM} \mathrm{NaCl}, 5 \%$ Glycerol, $1 \mathrm{mM}$ DTT). Reactions were stopped and analysed by immunoblot analysis. A modified protocol was used for the cleavage assay shown in Figure $4 \mathrm{c}$ owing to difficulties to obtain sufficient amounts of active Sf-caspase-V5. Note, under unmodified conditions the relative amounts of generated active drICE, Ag-caspase and Sf-caspase are 50:5:1 (measured by V5 antibody). For Figure 4c, SfIAP-TAP was purified using IgG Sepharose beads (as described above) and subsequently incubated with 293T lysate containing active Sf-caspase-V5. For Figure $2 f-h$, apoptosis of Sua 4.1 cells $\left(1 \times 10^{6}\right.$ cells) was induced by treatment with $50 \mu \mathrm{M}$ Etoposide for $24 \mathrm{~h}$, at which point $40 \%$ of cells displayed apoptotic morphologies. Apoptosis of Sf9 cells $\left(1 \times 10^{6}\right.$ cells $)$ was triggered by exposure to $60 \mu \mathrm{M} M \mathrm{MG} 132$ for $48 \mathrm{~h}$. Cell death of $\mathrm{BmN}$ cells $\left(1 \times 10^{4}\right.$ cells) was induced with UV and harvested $24 \mathrm{~h}$ later. Cells were lysed in $1 \%$ Triton Lysis buffer supplemented with $1 \mathrm{mM}$ DTT and the lysate centrifuged for $30 \mathrm{~min}$ at $16000 \mathrm{~g}$. The supernatant was used for the cleavage assay, which was performed for $3 \mathrm{~h}$ at $4^{\circ} \mathrm{C}$.

Cell-based killing assay. S2 cells were cultured as described previously. ${ }^{7}$ Apoptosis assays were performed as following. Briefly, $0.20 \mu \mathrm{g}$ of wild-type or mutant iap pAc5.1 was co-transfected with $0.30 \mu \mathrm{g}$ of rpr pAc5.1 and $0.03 \mu \mathrm{g} \mathrm{plE} 1$ 3 - $\beta$-galactosidase (Novagen, USA) into each well of a 24-well plate of S2 cells using Cellfectin (Invitrogen, USA). At $24 \mathrm{~h}$ post-transfection, cells were fixed and stained for LacZ activity and the number of blue cells were counted and used as indicator of cell survival as described previously. ${ }^{15,22}$ Four independent experiments were carried out and the mean and standard error calculated. To account for differences in transfection efficiencies associated with the various IAP plasmid preparations, quadruplicate experiments were performed, whereby one out of the four experiments was exposed to Z-VAD-fmk. Z-VAD-fmk blocks apoptosis and therefore served as transfection efficiency control. The number of blue cells of this well was set as $100 \%$, indicating the maximum number of transfected cells. Subsequently, we arbitrarily anchored the species-specific values of the normalised reference experiment (e.g. setting as $100 \%$ the WT IAPs for Figure $5 \mathrm{~d}$ and the $\mathrm{M}$-degrons for Figure $5 \mathrm{e}$ and $\mathrm{f}$ ) and expressed the efficiency of other IAP constructs 
in relation to it. The following regions of the corresponding coding sequences were used to generate RNAi: ate-1 (10-799 nt), ntan1 (1-727 nt).

$\mathrm{N}$-end rule expression analysis. RAT1 cells were transfected and treated as described previously. ${ }^{15}$ Briefly, Ub-fusion constructs were prepared in pDNA3 and transfected with FUGENE6 (Roche). Cells were treated with lactacystin for $6 \mathrm{~h}$ before lysis.

Acknowledgements. We thank Jim Nishiura for AalAP, Silkbase (http:// papilio.ab.a.u-tokyo.ac.jp/silkbase/index.html) for BmIAP, Nor Chejanovsky and Qihong Huang for Sf- and Bm-caspases, Hans-Michael Mueller for Sua4.1 cells, Colin Duckett for OpIAP3, Doreen Winstanley for CpGV, Motoko Ikeda for HcNVPIAP3, David Baker for BmN cells and Alexander Varshavsky, F Levy, B Seraphin, $B$ Prud'homme for reagents. We are indebted to François Leulier, Paulo Ribeiro and Andreas Bergmann for critical reading of the manuscript.

1. Danial NN, Korsmeyer SJ. Cell death: critical control points. Cell 2004; 116: 205-219.

2. Vaux DL, Silke J. IAPs RINGs and ubiquitylation. Nat Rev Mol Cell Biol 2005; 6: 287-297.

3. Riedl SJ, Shi Y. Molecular mechanisms of caspase regulation during apoptosis. Nat Rev Mol Cell Biol 2004; 5: 897-907.

4. Kornbluth S, White K. Apoptosis in Drosophila: neither fish nor fowl (nor man, nor worm) J Cell Sci 2005; 118: 1779-1787.

5. Lisi S, Mazzon I, White K. Diverse domains of THREAD/DIAP1 are required to inhibit apoptosis induced by REAPER and HID in Drosophila. Genetics 2000; 154: 669-678.

6. Wilson R, Goyal L, Ditzel M, Zachariou A, Baker DA, Agapite J et al. The DIAP1 RING finger mediates ubiquitination of Dronc and is indispensable for regulating apoptosis. Nat Cell Biol 2002; 4: 445-450.

7. Meier P, Silke J, Leevers SJ, Evan GI. The Drosophila caspase DRONC is regulated by DIAP1. EMBO J 2000; 19: 598-611.

8. Varshavsky A. The N-end rule: functions, mysteries, uses. Proc Natl Acad Sci USA 1996; 93: 12142-12149.

9. Tasaki T, Mulder LC, Iwamatsu A, Lee MJ, Davydov IV, Varshavsky A et al. A family of mammalian E3 ubiquitin ligases that contain the UBR box motif and recognize $\mathrm{N}$-degrons. Mol Cell Biol 2005; 25: 7120-7136.

10. Xie Y, Varshavsky A. The E2-E3 interaction in the N-end rule pathway: the RING-H2 finge of $E 3$ is required for the synthesis of multiubiquitin chain. EMBO J 1999; 18: 6832-6844.

11. An JY, Seo JW, Tasaki T, Lee MJ, Varshavsky A, Kwon YT. Impaired neurogenesis and cardiovascular development in mice lacking the E3 ubiquitin ligases UBR1 and UBR2 of the N-end rule pathway. Proc Natl Acad Sci USA 2006; 103: 6212-6217.

12. Kwon YT, Xia Z, An JY, Tasaki T, Davydov IV, Seo JW et al. Female lethality and apoptosis of spermatocytes in mice lacking the UBR2 ubiquitin ligase of the N-end rule pathway. Mol Cell Biol 2003; 23: 8255-8271.

13. Zenker M, Mayerle J, Lerch MM, Tagariello A, Zerres K, Durie PR et al. Deficiency of UBR1, a ubiquitin ligase of the $\mathrm{N}$-end rule pathway, causes pancreatic dysfunction, malformations and mental retardation (Johanson-Blizzard syndrome). Nat Genet 2005; 37 $1345-1350$.

14. Erbse A, Schmidt R, Bornemann T, Schneider-Mergener J, Mogk A, Zahn R et al. ClpS is an essential component of the N-end rule pathway in Escherichia coli. Nature 2006; 439 : 753-756.

15. Ditzel M, Wilson R, Tenev T, Zachariou A, Paul A, Deas E et al. Degradation of DIAP by the N-end rule pathway is essential for regulating apoptosis. Nat Cell Biol 2003; 5 : 467-473.

16. Tenev $T$, Zachariou A, Wilson R, Ditzel M, Meier P. IAPs are functionally non-equivalen and regulate effector caspases through distinct mechanisms. Nat Cell Biol 2005; 7: 70-77.

17. Yan N, Wu JW, Chai J, Li W, Shi Y. Molecular mechanisms of DrICE inhibition by DIAP1 and removal of inhibition by Reaper, Hid and Grim. Nat Struct Mol Biol 2004; 11: 420-428.

18. Muro I, Means JC, Clem RJ. Cleavage of the apoptosis inhibitor DIAP1 by the apical caspase DRONC in both normal and apoptotic Drosophila cells. J Biol Chem 2005; 280 : 18683-18688.

19. Yokokura T, Dresnek D, Huseinovic N, Lisi S, Abdelwahid E, Bangs $P$ et al. Dissection of DIAP1 functional domains via a mutant replacement strategy. J Biol Chem 2004; 279 : 52603-52612.
20. Burmester T, Massey Jr HC, Zakharkin SO, Benes $\mathrm{H}$. The evolution of hexamerins and the phylogeny of insects. J Mol Evol 1998; 47: 93-108

21. Burmester T. Molecular evolution of the arthropod hemocyanin superfamily. Mol Biol Evol 2001; 18: 184-195.

22. Goyal L, McCall K, Agapite J, Hartwieg E, Steller H. Induction of apoptosis by Drosophila reaper, hid and grim through inhibition of IAP function. EMBO J 2000; 19: 589-597.

23. Rodriguez A, Chen $\mathrm{P}$, Oliver $\mathrm{H}$, Abrams JM. Unrestrained caspase-dependent cell death caused by loss of Diap1 function requires the Drosophila Apaf-1 homolog, Dark. EMBO J 2002; 21: 2189-2197.

24. Wang SL, Hawkins CJ, Yoo SJ, Muller HA, Hay BA. The Drosophila caspase inhibitor DIAP1 is essential for cell survival and is negatively regulated by HID. Cell 1999; 98: 453-463

25. Conze DB, Albert L, Ferrick DA, Goeddel DV, Yeh WC, Mak T et al. Post-transcriptional downregulation of C-IAP2 by the ubiquitin protein ligase C-IAP1 in vivo. Mol Cell Biol 2005; 25: 3348-3356

26. Harlin H, Reffey SB, Duckett CS, Lindsten T, Thompson CB. Characterization of XIAPdeficient mice. Mol Cell Biol 2001; 21: 3604-3608.

27. Leulier F, Lhocine N, Lemaitre B, Meier P. The Drosophila inhibitor of apoptosis protein DIAP2 functions in innate immunity and is essential to resist gram-negative bacterial infection. Mol Cell Biol 2006; 26: 7821-7831.

28. Thornberry NA, Rano TA, Peterson EP, Rasper DM, Timkey T, Garcia-Calvo M et al. A combinatorial approach defines specificities of members of the caspase family and granzyme B. Functional relationships established for key mediators of apoptosis. J Biol Chem 1997; 272: 17907-17911.

29. Stennicke HR, Renatus M, Meldal M, Salvesen GS. Internally quenched fluorescent peptide substrates disclose the subsite preferences of human caspases 1, 3, 6, 7 and 8 . Biochem J 2000; 350 (Part 2): 563-568.

30. Rigaut G, Shevchenko A, Rutz B, Wilm M, Mann M, Seraphin B. A generic protein purification method for protein complex characterization and proteome exploration. Nat Biotechnol 1999; 17: 1030-1032.

31. Wright CW, Means JC, Penabaz T, Clem RJ. The baculovirus anti-apoptotic protein Op-IAP does not inhibit Drosophila caspases or apoptosis in Drosophila S2 cells and instead sensitizes S2 cells to virus-induced apoptosis. Virology 2005; 335: 61-71.

32. Bachmair A, Finley D, Varshavsky A. In vivo half-life of a protein is a function of its aminoterminal residue. Science 1986; 234: 179-186.

33. Hershko A, Ciechanover A, Varshavsky A. Basic medical research award. The ubiquitin system. Nat Med 2000; 6: 1073-1081.

34. Leulier F, Ribeiro PS, Palmer E, Tenev T, Takahashi K, Robertson D et al. Systematic in vivo RNAi analysis of putative components of the Drosophila cell death machinery. Cell Death Differ 2006; 13: 1663-1674.

35. Muro I, Berry DL, Huh JR, Chen $\mathrm{CH}$, Huang H, Yoo SJ et al. The Drosophila caspase Ice is important for many apoptotic cell deaths and for spermatid individualization, a nonapoptotic process. Development 2006; 133: 3305-3315.

36. Xu D, Wang Y, Willecke R, Chen Z, Ding T, Bergmann A. The effector caspases drICE and $\mathrm{dcp}-1$ have partially overlapping functions in the apoptotic pathway in Drosophila. Cell Death Differ 2006; 13: 1697-1706.

37. Zachariou A, Tenev T, Goyal L, Agapite J, Steller H, Meier P. IAP-antagonists exhibit nonredundant modes of action through differential DIAP1 binding. EMBO J 2003; 22: $6642-6652$.

38. Wilkinson JC, Wilkinson AS, Scott FL, Csomos RA, Salvesen GS, Duckett CS. Neutralization of Smac/Diablo by inhibitors of apoptosis (IAPs). A caspase-independent mechanism for apoptotic inhibition. J Biol Chem 2004; 279: 51082-51090.

39. Vucic D, Kaiser WJ, Harvey AJ, Miller LK. Inhibition of reaper-induced apoptosis by interaction with inhibitor of apoptosis proteins (IAPs). Proc Natl Acad Sci USA 1997; 94: 10183-10188.

40. Huang Q, Deveraux QL, Maeda S, Salvesen GS, Stennicke HR, Hammock BD et al. Evolutionary conservation of apoptosis mechanisms: lepidopteran and baculoviral inhibitor of apoptosis proteins are inhibitors of mammalian caspase-9. Proc Natl Acad Sci USA 2000; 97: 1427-1432.

41. Thompson JD, Gibson TJ, Plewniak F, Jeanmougin F, Higgins DG. The CLUSTAL $X$ windows interface: flexible strategies for multiple sequence alignment aided by quality analysis tools. Nucleic Acids Res 1997; 25: 4876-4882.

42. Thompson JD, Higgins DG, Gibson TJ. CLUSTAL W: improving the sensitivity of progressive multiple sequence alignment through sequence weighting, position-specific gap penalties and weight matrix choice. Nucleic Acids Res 1994; 22: 4673-4680.

Supplementary Information accompanies the paper on Cell Death and Differentiation website (http://www.nature.com/cdd) 